\title{
Consignação de estratégias a partir da análise ambiental: um estudo de caso do Grupo Jan Bebidas
}

\author{
Deosir Flávio Lobo de Castro Jr ${ }^{1}$ \\ Elvis Silveira-Martins ${ }^{2}$ \\ Márcio Nakayama Miura ${ }^{3}$ \\ Marcos Alexandre Schiavoni ${ }^{4}$ \\ Marcelo Augusto Menezes Deluca ${ }^{5}$
}

\begin{abstract}
RESUMO
O objetivo da presente pesquisa é o de descrever e analisar o processo adaptativo do Grupo JAN Bebidas do período de 1992 até 2010, partindo do modelo de adaptação estratégica proposto por Hrebiniak e Joyce (1985). Registra-se que outros estudos também foram considerados como Astley e Van de Ven (1983) e Aldrich e Pfeffer (1976), no que tange às mudanças estratégicas, e o modelo de Miles e Snow (1978) para verificar a postura estratégica dos diretores do Grupo JAN Bebidas. Quanto a metodologia, o estudo caracteriza-se como longitudinal, com abordagem qualitativa e descritiva. Assim, para a investigação, utilizou-se o método do estudo de caso. Na coleta dos dados, valendo-se da entrevista com diretores das áreas comercial e de produção, baseada em roteiro semi-estruturado. Assim, foi possível descrever o processo de adaptação estratégica e verificar que os principais fatores da adaptação foram causados por restrições ambientais.
\end{abstract}

Palavras-chave: Estratégia. Setor Produtivo. Bebidas.

\section{INTRODUÇÃO}

O processo de adaptação ao ambiente caracteriza a administração estratégica e exige dos gestores não somente o desafio de enfrentar as mudanças ocorridas no ambiente da organização, mas também lidar com mudanças causadas pelos processos internos à estrutura organizacional.

Segundo Cândido e Abreu (2000), o aumento e a complexidade desse ambiente devem-se, principalmente, à economia, ao avanço tecnológico, ao desenvolvimento de processos e produtos, ao crescimento de concorrências, às novas exigências políticas e sociais, às crescentes flutuações nos mercados, causando aumento do grau de riscos e incertezas.

Considerando essa realidade, esta pesquisa pretende estabelecer como se apresentam as mudanças ambientais à luz do modelo adaptativo e qual a postura estratégica dos gestores do Grupo JAN Bebidas.

\footnotetext{
${ }^{1}$ Doutor em Administração e Turismo. Instituto Federal de Santa Catarina - deosir@ifsc.edu.br

${ }^{2}$ Doutor em Administração e Turismo. Universidade Federal de Pelotas - elvis.professor@gmail.com

${ }^{3}$ Doutor em Administração e Turismo. Unioeste - adm.parana@gmail.com

${ }^{4}$ Mestre em Administração. Unicesumar - mschiavoni@gmail.com

${ }^{5}$ Mestre em Administração. UFSC - mdeluca@linhalivre.net
} 


\subsection{Objetivo geral}

Compreender a adaptação ambiental do Grupo JAN Bebidas, do período de 1992 até 2010, com base na postura estratégica adotada por seus diretores.

\subsection{Objetivos específicos}

a) Analisar os componentes do ciclo adaptativo estratégico do Grupo JAN Bebidas.

b) Identificar o comportamento estratégico proeminente do Grupo JAN Bebidas.

c) Caracterizar a escolha estratégica da organização.

\section{REFERENCIAL TEÓRICO}

A discussão teórica fundamenta-se nos estudos sobre ambiente organizacional, mudanças e tipologia estratégica. Com base nas teorias que permeiam esses temas, procurou-se investigar os caminhos para os tomadores de decisão do Grupo JAN Bebidas.

\subsection{Ambiente organizacional}

Embora os pioneiros da administração tivessem as suas preocupações voltadas para a parte interna das organizações, o ambiente externo passava, cada vez mais, a influenciar as organizações, principalmente após a Segunda Guerra Mundial.

Muito do difundido interesse na estratégia e na mudança organizacional deriva da percepção de que as organizações devem ser sensíveis ao que ocorre no mundo que as rodeia. De acordo com Marucci e Machadoda-Silva (2001) e Silveira-Martins et al. (2006), o termo ambiente é utilizado para justificar as mudanças e a dinâmica das alterações que ocorrem nas organizações. Segundo Mintzberg, Ahlstrand e Lampel (2000), e Pereira (2000), o ambiente pode ser visto como sendo um conjunto de forças externas à empresa, que esta não pode controlar nem dirigir conforme a sua vontade.

Perseguindo essa linha de investigação, outros teóricos organizacionais, tais como Morgan (1995) e Pereira (2000), verificaram que as mudanças que ocorrem no ambiente externo poderão gerar conflitos dentro das organizações, eliminando-as do ambiente competitivo ou, pelo contrário, tornando-as mais competitivas. Entretanto, uma organização tem o poder de igualmente influenciar e alterar o seu ambiente externo, observam outros pesquisadores, entre eles Brito e Fachin (2001) e Silveira-Martins et al. (2006).

A partir da década de 1950, os teóricos organizacionais começaram a inspirar-se, sobretudo na biologia e na Teoria Geral dos Sistemas, como uma fonte de ideias para refletir sobre as organizações. Nessa abordagem, uma organização forma um campo dinâmico de forças que interagem entre si, apresentando um efeito sistêmico. Todavia, a dinâmica e a intensidade das mudanças no ambiente forçam a organização a adaptar-se com respostas rápidas a fim de evitar a entropia organizacional (TREGOE; ZIMMERMAN, 1980; SILVA; REBELO, 2003; SILVEIRA-MARTINS et al., 2006). Ou seja, para sobreviver, as organizações, à semelhança dos organismos biológicos, devem desenvolver a capacidade de interagir e ajustar-se constantemente ao meio em que vivem.

Da mesma forma, Tushman e Nadler (1997), Mintzberg, Ahlstrand e Lampel (2000), e Motta (2006) consideram que a inovação em processos mercadológicos, produtivos, tecnológicos ou administrativos oportuniza o aprendizado incremental em relação à mudança e possíveis experimentações devendo, portanto, incorporar as variações produzidas no âmbito social, técnico e interno, e também pelas provocações ambientais no campo externo às organizações.

Mas, qual a origem das mudanças? Cada abordagem na teoria organizacional agregou novos elementos para a compreensão de como organizações lidam com o ambiente e com as mudanças. Dentre as orientações, destacam-se a vertente determinista, que advoga que o ambiente influencia e restringe as ações organizacionais; e a vertente voluntarista, que advoga que as organizações decidem como efetuar a mudança organizacional, adaptando-se de forma mais reativa, ou influenciando o ambiente de forma proativa.

Na perspectiva voluntarista, Miles (1980) reconhece o papel da escolha estratégica. Essa perspectiva enfatiza o aprendizado e a escolha no processo de adaptação organizacional. Seguindo nessa linha, Pettigrew (1987) igualmente afirma que as organizações, com o passar do tempo, sofrem transformações para se manter no ambiente. Entretanto, segundo esse autor, as razões dessas mudanças podem ocorrer pela imposição do contexto no qual a organização está inserida ou por vontade própria de seus gestores. Mas, 
as raízes desse enfoque encontram-se nos estudos a propósito da adaptação ao ambiente organizacional, tais quais os realizados por Aldrich e Pfeffer (1976a, 1976b), Astley e Van de Ven (1983), Hrebiniak e Joyce (1985) e, mais recentemente, as pesquisas de Rossetto, Lazareti e Vargas (2012), ajudam entender a reflexão sobre o tema. Afirmam esses autores que as variáveis não controláveis pela organização, pela sua relevância e implicância aos seus resultados, merecem ser monitorados, uma vez que a organização pode ou deve alterar ou reinventar-se para se adaptar ao ambiente.

Astley e Van de Ven (1983) questionam se a vida organizacional é determinada por restrições ambientais intratáveis, ou se ela é criada ativamente por decisões gerenciais estratégicas. Seriam, portanto, os gestores agentes autônomos e proativos, ou somente agiriam os gestores de maneira reativa às condições de seu ambiente?

Teorias ajudam a dar objetividade às práticas à que se referem, ao explicar os fenômenos organizacionais. Muito embora existam pesquisas, como de Astley e Van de Ven (1983), que consideram excludentes o determinismo ambiental e a escolha estratégica, há, outros autores, como Hrebiniak e Joyce (1985), que diferentemente não consideram como sendo duas categorias mutuamente exclusivas.

Aldrich e Pfeffer (1976a) já observaram que, apesar de parecerem completamente diferentes, tanto o determinismo ambiental como a escolha estratégica, do ambiente organizacional resulta a performance da organização.

Rossetto e Rosseto (2005) asseveram que, na percepção de Miles (1980), ambas as visões que tangem tanto o determinismo, como o voluntarismo deveriam ser alteradas do 'se', assumindo a existência da possibilidade, para 'quando', o momento que ocorrerá. Assumindo, desse modo, que os elementos da vontade própria e do determinismo ambiental estarão presentes.

No entanto, Pettigrew (1987) observou a falta de estudos significativos a respeito de mudança, os quais possibilitem uma visão de maneira temporal e contextual. Ressalta-se a importância de desenvolver um estudo longitudinal para verificar a interdependência entre níveis mais altos e mais baixos - análise vertical - e também as interconexões entre fenômenos nos tempos históricos, presente e futuro - análise horizontal.

Destaca-se o modelo de Hrebiniak e Joyce (1985), o qual apresenta quatro posições possíveis de uma organização. Na Figura 1, são apresentados os quatro quadrantes em relação ao grau de determinismo e a possibilidade de escolha estratégica.

Figura 1 - Escolhas estratégicas e determinismo ambiental

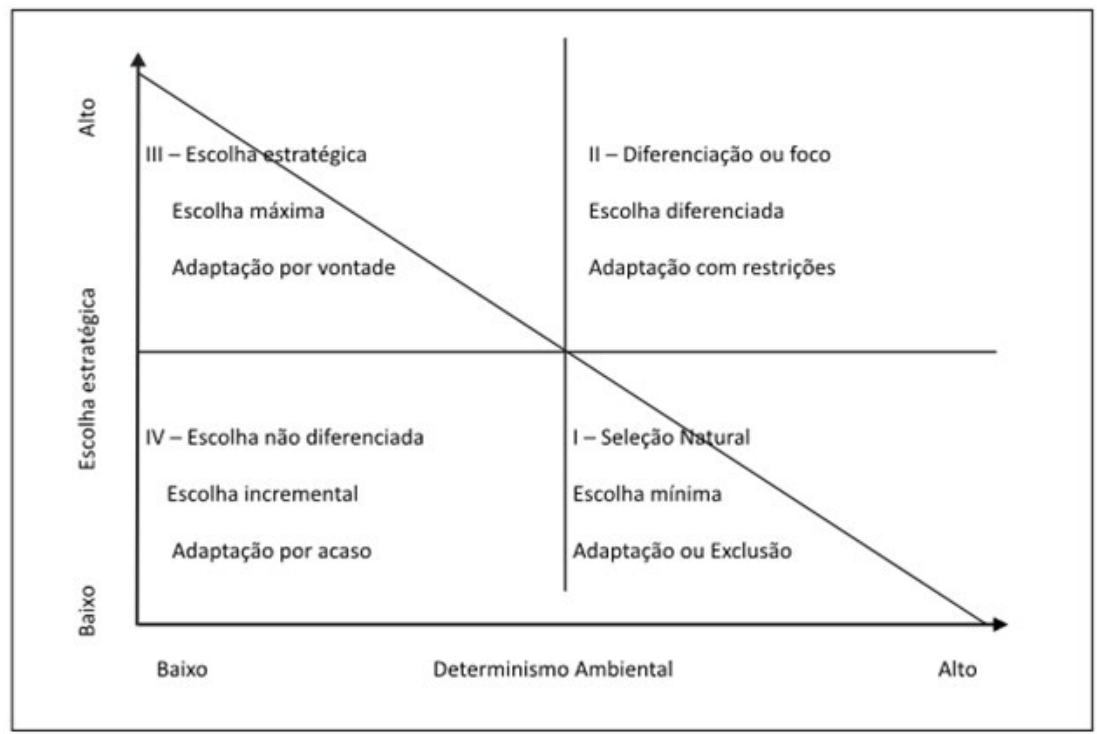

Fonte: Adaptado de Hrebiniak e Joyce (1985)

De acordo com Hrebiniak e Joyce (1985), cada quadrante representa uma forma de lidar com o ambiente. Sendo assim, o primeiro quadrante - representa a seleção natural, em que a organização, ou busca a adaptação, ou será eliminada, ou seja, capacidade de escolha baixa. Segundo quadrante - existe alta capacidade de escolha. Neste quadrante, existe a diferenciação das organizações, no entanto, sua adaptação é com restrições. Terceiro quadrante - existe a escolha estratégica máxima. Quarto quadrante - a adaptação é por acaso, uma escolha incremental. 
De acordo com Aldrich e Pfeffer (1976a, 1976b), ambos os modelos, tanto o da seleção natural quanto o da escolha estratégica concordam com a importância do ambiente organizacional para entender as decisões e estruturas organizacionais. A diferença entre os modelos reside na evolução da importância do papel da seleção ambiental. A literatura atual possui elementos de ambas as perspectivas, embora incompletas.

Todavia, sabemos que, enquanto no modelo de seleção natural não existe espaço para uma organização desenvolver uma estratégia, o modelo da escolha estratégica acredita que exista tal possibilidade. Neste estudo, buscou-se a demonstração dessas mudanças, já incorporadas ao ambiente organizacional, evidenciadas no dia a dia do Grupo JAN Bebidas, conforme as percepções de seus gestores.

\subsection{Mudança estratégica}

Teóricos que propagam a tese das mudanças organizacionais suportam suas pesquisas por métodos adaptativos. 0 entendimento dos objetivos e metas organizacionais - qualitativos e quantitativos -, a busca por eficiência organizacional, as formas de buscar e de se perceber as informações, podendo ser observação direta, observação condicionada, pesquisa formal ou pesquisa informal, são fonte de pesquisas que procuram entender as mudanças organizacionais (AGUILAR, 1967).

As mudanças organizacionais, muitas vezes são impulsionadas por restrições impostas pelo ambiente. Sob essa lógica, a empresa deverá buscar a flexibilidade como uma proteção contra 'catástrofes organizacionais', procurando alternativas estratégicas para as mesmas (ANSOFF, 1977; ROSSETTO; ROSSETTO, 2005).

As mudanças organizacionais não ocorrem por acaso, simplesmente do nada, sem um embasamento ou alicerce contextual. 0 contexto está intrinsecamente ligado aos fatores internos e aos fatores externos à organização, que influenciam os resultados. É necessário entender o contexto, o conteúdo e a forma das mudanças se faz obrigatório para o pensamento estratégico. Além disso, procurar entender as necessidades da organização e de seus stakeholders, da mesma forma como se procura entender as dos clientes, estabelecer os processos de negociação com todos os stakeholders, entender as ações dos stakeholders em vez de reagir contra elas e alocar recursos com base no grau de importância da turbulência ambiental (FREEMAN; REED, 1983; PETTIGREW, 1987).

Cancellier et al. (2009) ressaltam que na literatura um dos principais fatores externos considerados influentes para a competitividade organizacional é a concorrência. Com o mercado competitivo, uma postura estratégica busca conseguir manter-se no mercado e uma vantagem em relação aos seus competidores, ou seja, seus concorrentes. Contudo, uma característica investigada em relação às pequenas empresas, por Fann e Smeltzer (1989), é o fato de elas, ao acreditar em demasia na qualidade de seu produto, não valorizarem as informações da concorrência.

Corroborando com os estudos de Fann e Smeltzer (1989), Cancellier e Alberton (2008) verificaram que dentre as informações sobre seus clientes e consumidores as normas reguladoras são as mais monitoradas, e que as informações sobre concorrentes estão entre as menos monitoradas.

Ainda em relação ao monitoramento ambiental, Cancellier (2001) identificou, em seu estudo, que os gestores estão monitorando o ambiente mais em busca de oportunidades e ignoram as ameaças competitivas.

Autores como Miller e Dess (1993) e Silveira-Martins, Predebon e Maia (2008) destacam o cuidado com as mudanças estratégicas e com possíveis desequilíbrios na organização. Seja no que tange à sua estrutura, ou aos seus processos, podendo vir a resultar na busca incessante de ajustes internos, em que a incerteza manifesta-se como desafio nas tomadas de decisões do corpo gerencial.

\subsection{Tipologia estratégica}

De acordo com Fernandes, Silva e Cândido (2007), o modelo de Porter (1980) ainda continua sendo o modelo estratégico mais conhecido. Apesar de sua ampla utilização, o modelo de Porter (1980) recebe críticas pela sua impossibilidade da classificação de todos os tipos de estratégia (CARNEIRO; CAVALCANTI; SILVA, 1997).

Conant, Mokwa e Varadarajan (1990), e Gimenez et al. (1999) defendem a taxonomia de Miles e Snow (1978), como sendo a alternativa que chama a atenção exatamente por possuir qualidade conceitual.

McDaniel e Kolari (1987) salientam que a tipologia estratégica desenvolvida por Miles e Snow (1978) é uma estrutura teórica útil para a análise das formas em que as organizações interagem com seu ambiente e as estratégias subsequentes que deveriam ser adotadas. Zahra e Pearce (1990) lembram que a tipologia de Miles e Snow foi a tipologia mais popular nas pesquisas de estratégias de negócio nos anos 1980.

Hambrick (2003) afirma que, dentre os modelos de análise do comportamento estratégico, introduzidos 
ao longo dos últimos 25 anos, a tipologia de Miles e Snow (1978) tem sido a mais duradoura, a mais crítica, além de ser a mais utilizada em estudos desta natureza. Essa metodologia foi submetida a vários testes de validade. Em uma ampla gama de configurações, os pesquisadores descobriram forte e consistente suporte para validar o modelo.

A base do trabalho de Miles e Snow (1978) baseia-se em três pontos - o ambiente, a estrutura da organização e as estratégias competitivas - os quais dão origem ao ciclo Adaptativo. Na Figura 2 apresentase a relação entre esses pontos.

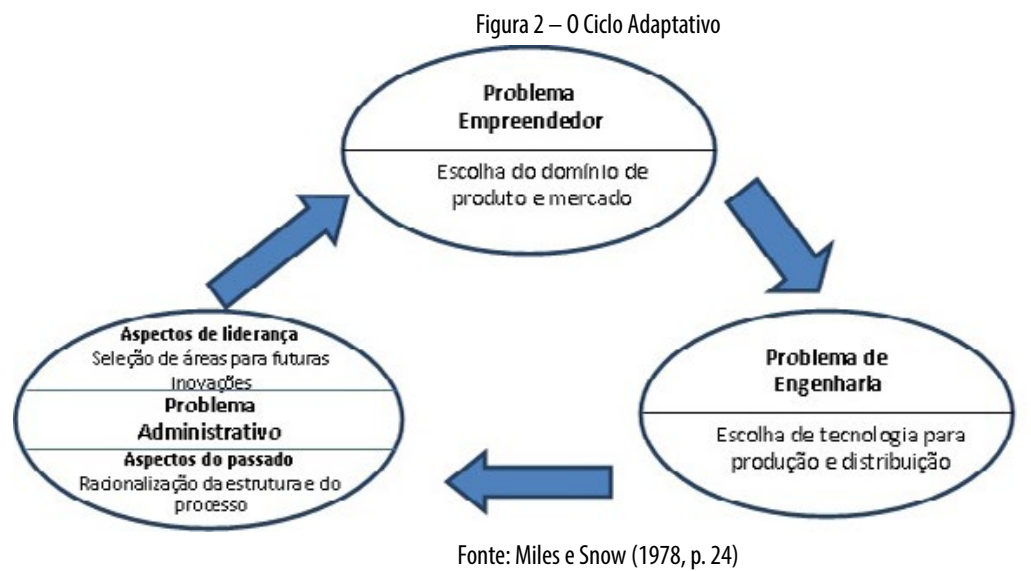

Pela tipologia de Miles e Snow (1978), a postura estratégica pode ser enquadrada em quatro categorias teóricas: Defensiva, Prospectora, Analítica e Reativa. No Quadro 1, são apresentadas as características de cada estratégia.

Quadro 1 - Categorias Estratégicas de Miles e Snow

\begin{tabular}{|c|c|}
\hline Categoria Estratégica & \multicolumn{1}{c|}{ DESCRIÇÃO } \\
\hline Estratégia Defensiva & $\begin{array}{c}\text { Uma empresa, seguindo esta estratégia, procura localizar e manter uma linha de produtos/serviços } \\
\text { relativamente estável. Seu foco concentra-se em uma gama de produtos/serviços mais limitada do que } \\
\text { seus concorrentes e tenta proteger seu domínio por meio da oferta de produtos com melhor qualidade, } \\
\text { serviços superiores, e/ou menores preços. Não procura estar entre os líderes da indústria, restringindo-se } \\
\text { àquilo que sabe fazer tão bem, ou melhor, que qualquer um. }\end{array}$ \\
\hline Estratégia Prospectora & $\begin{array}{c}\text { Uma empresa que adota esta estratégia está continuamente ampliando sua linha de produtos/serviços. } \\
\text { Enfatiza a importância de oferecer novos produtos/serviços em uma área de mercado relativamente mais } \\
\text { ampla. Valoriza ser uma das primeiras a oferecer novos produtos, mesmo que todos os esforços não se } \\
\text { mostrem altamente lucrativos. }\end{array}$ \\
\hline Estratégia Analítica & $\begin{array}{c}\text { Uma empresa que segue esta estratégia tenta manter uma linha limitada de produtos/serviços relati- } \\
\text { vamente estável e, ao mesmo tempo, tenta adicionar um ou mais novos produtos/serviços que foram } \\
\text { bem-sucedidos em outras empresas do setor. Em muitos aspectos é uma posição intermediária entre as } \\
\text { estratégias defensiva e prospectora. }\end{array}$ \\
\hline Estratégia Reativa & $\begin{array}{c}\text { A firma que adota uma estratégia reativa exibe um comportamento mais inconsistente do que os outros } \\
\text { tipos. É uma espécie de não estratégia. Não arrisca em novos produtos/serviços a não ser quando amea- } \\
\text { çada por competidores. A abordagem típica é "esperar para ver" e responder somente quando forçada por } \\
\text { pressões competitivas para evitar a perda de clientes importantes e/ou manter lucratividade. }\end{array}$ \\
\hline
\end{tabular}

Fonte: Gimenez (1999)

Partindo das categorias das posturas estratégicas, e sua descrição, Gimenez (1999) e Rossetto (2000) creditam às personalidades dos principais gestores em qualquer organização a função importante de explorar as escolhas estratégicas por meio da avaliação do papel exercido pelas características pessoais de tomadores de decisão em empresas.

A relação entre os tipos de problemas e o comportamento adotado é diferenciada para cada situação, conforme é possível verificar, de maneira detalhada, no Quadro 2. 
Quadro 2 - Tipologias Estratégicas e Caracterização

\begin{tabular}{|c|c|c|c|c|c|}
\hline \multirow{2}{*}{$\begin{array}{c}\text { Componentes do ciclo } \\
\text { adaptativo }\end{array}$} & \multirow{2}{*}{ Dimensões } & \multicolumn{4}{|c|}{ Comportamentos Estratégicos } \\
\hline & & Defensor & Prospector & Analista & Reativo \\
\hline \multirow{4}{*}{$\begin{array}{l}\text { Problema } \\
\text { Empreendedor e } \\
\text { Soluções }\end{array}$} & $\begin{array}{l}\text { Domínio de produtose } \\
\text { mercados }\end{array}$ & $\begin{array}{l}\text { Estreito e cuidadosa- } \\
\text { mente focado }\end{array}$ & $\begin{array}{l}\text { Amplo e em expansão } \\
\text { contínua }\end{array}$ & $\begin{array}{l}\text { Segmentado e cuidado- } \\
\text { samente ajustado }\end{array}$ & Irregular e transitório \\
\hline & Postura de sucesso & $\begin{array}{l}\text { Proeminente em seu } \\
\text { mercado }\end{array}$ & $\begin{array}{l}\text { Ativa iniciaçãa de } \\
\text { mudaça }\end{array}$ & $\begin{array}{c}\text { Seguidores cuidadosos } \\
\text { de mudança }\end{array}$ & $\begin{array}{l}\text { Investidas oportunistas } \\
\text { e postura de adaptação }\end{array}$ \\
\hline & $\begin{array}{l}\text { Monitoramento } \\
\text { ambiental }\end{array}$ & $\begin{array}{l}\text { Baseado no domínio e } \\
\text { cuidadoso/forte monito- } \\
\text { ramento organizacional }\end{array}$ & $\begin{array}{c}\text { Orientado para o } \\
\text { mercado e ambiente/ } \\
\text { busca agressiva }\end{array}$ & $\begin{array}{l}\text { Orientado para a concor- } \\
\text { rência e completo }\end{array}$ & $\begin{array}{l}\text { Esporádico e dominado } \\
\text { por tópicos específicos }\end{array}$ \\
\hline & Crescimento & $\begin{array}{c}\text { Penetração cuidadosa e } \\
\text { avanços de produti- } \\
\text { vidade }\end{array}$ & $\begin{array}{l}\text { Desenvolvimento de } \\
\text { produtos e mercados e } \\
\text { diversificação }\end{array}$ & $\begin{array}{l}\text { Penetração assertiva e } \\
\text { cuidadoso desenvolvi- } \\
\text { mento de produtos e } \\
\text { mercados }\end{array}$ & Mudanças apressadas \\
\hline \multirow{3}{*}{$\begin{array}{l}\text { Problema de } \\
\text { Engenharia e } \\
\text { Soluções }\end{array}$} & Objetivo tecnológico & Eficiência de custos & Flexibilidade e inovação & Sinergia tecnológica & $\begin{array}{l}\text { Desenvolvimento e } \\
\text { conclusão de projetos }\end{array}$ \\
\hline & Amplitude tecnológica & $\begin{array}{l}\text { Tecnologia única, focal/ } \\
\text { expertise básica }\end{array}$ & $\begin{array}{l}\text { Tecnologias múltiplas/ } \\
\text { avançando na fronteira }\end{array}$ & $\begin{array}{l}\text { Tecnologias interrelacio- } \\
\text { nadas na fronteira }\end{array}$ & $\begin{array}{c}\text { Aplicações tecnológicas } \\
\text { mutáveis/fluidez }\end{array}$ \\
\hline & $\begin{array}{l}\text { Anteparos tecnológicos } \\
\text { (buffers) }\end{array}$ & $\begin{array}{l}\text { Programas de manuten- } \\
\text { ção e padronização }\end{array}$ & $\begin{array}{l}\text { Habilidades de pessoal } \\
\text { técnico/ diversidade }\end{array}$ & $\begin{array}{l}\text { Incrementalismo e } \\
\text { sinergia }\end{array}$ & $\begin{array}{l}\text { Habilidade de experi- } \\
\text { mentar e improvisar } \\
\text { soluções }\end{array}$ \\
\hline \multirow{4}{*}{$\begin{array}{c}\text { Problema } \\
\text { Administrativo e } \\
\text { Soluções }\end{array}$} & Coalizão dominante & Finanças e Produção & Marketing e P\&D & $\begin{array}{l}\text { Pessoal de Planeja- } \\
\text { mento }\end{array}$ & $\begin{array}{c}\text { Solucionadores de } \\
\text { problemas }\end{array}$ \\
\hline & Planejamento & $\begin{array}{l}\text { De dentro para fora/ } \\
\text { dominado por controle }\end{array}$ & $\begin{array}{c}\text { Busca de problemas e } \\
\text { oportunidades/ pers- } \\
\text { pectiva de programas ou } \\
\text { campanhas }\end{array}$ & $\begin{array}{l}\text { Abrangente com mu- } \\
\text { danças incrementais }\end{array}$ & $\begin{array}{l}\text { Orientado por crises e } \\
\text { desarticulado }\end{array}$ \\
\hline & Estrutura & $\begin{array}{l}\text { Funcional/ Autoridade } \\
\text { de linha }\end{array}$ & $\begin{array}{l}\text { Por produtos e/ou } \\
\text { mercados }\end{array}$ & $\begin{array}{c}\text { Dominada por asses- } \\
\text { sores/ orientada por } \\
\text { matriz }\end{array}$ & $\begin{array}{c}\text { Autoridade formal rígi- } \\
\text { da/desenho operacional } \\
\text { solto }\end{array}$ \\
\hline & Controle & $\begin{array}{l}\text { Centralizado, formal e } \\
\text { ancorado em aspectos } \\
\text { financeiros }\end{array}$ & $\begin{array}{l}\text { Desempenho no merca- } \\
\text { do/volume de vendas }\end{array}$ & $\begin{array}{l}\text { Métodos múltiplos/ } \\
\text { cálculos de riscos } \\
\text { cuidadosos/contribuição } \\
\text { de vendas }\end{array}$ & $\begin{array}{l}\text { Evitar problemas/ } \\
\text { resolver problemas } \\
\text { remanescentes }\end{array}$ \\
\hline
\end{tabular}

Fonte: Conant, Mokwa e Varadarajan (1990, p. 367) e Gimenez et al. (1999, p. 61)

De acordo com Brunaldi, Jungles e Gimenez (2007), a escolha estratégica está, normalmente, a cargo de uma única pessoa, podendo ser o gerente ou o proprietário, podendo a personalidade deste tomador de decisão moldar a estratégia adotada.

\section{METODOLOGIA}

De acordo com Pettigrew (1987), o indicado para que se possa estudar a mudança em uma organização é verificar a sua história; sendo imprescindível que se conheça o seu contexto, conteúdo e processo. Este estudo longitudinal favorece as análises verticais e horizontais.

Por ser uma pesquisa descritiva, de acordo com Hoppen, Lapointe e Moreau (1996), esta delineou o objeto analisado, buscando mapear o fenômeno na população estudada, neste estudo de caso, seus tomadores de decisão. Gil (2002) afirma que este método consiste no estudo profundo e exaustivo de um ou poucos objetos, de maneira que permita seu amplo e detalhado conhecimento.

Fachin (2001) da mesma forma caracteriza como um estudo intensivo, em que são levados em consideração, principalmente, a compreensão, como um todo, do assunto investigado. Segundo o autor, quando o estudo é intensivo podem até aparecer relações que, de outra forma, não seriam descobertas. Yin (2001) afirma também que o estudo de caso é um modo de pesquisa empírica que investiga fenômenos contemporâneos em seu ambiente real, quando os limites entre o fenômeno e o contexto não são claramente definidos; quando há mais variáveis de interesse do que pontos de dados; quando se baseia em várias fontes 
de evidências; e quando há proposições teóricas para conduzir a coleta e a análise dos dados.

0 presente estudo foi realizado em um grupo formado por três empresas no ramo de bebidas localizadas no estado de Santa Catarina. Como objeto da análise, considerou-se o Grupo JAN Bebidas por se tratar de uma empresa consolidada no segmento e que se disponibilizou a repassar as informações necessárias para o pleno desenvolvimento deste estudo de caso.

Entrevistas semiestruturadas presenciais foram programadas com o Diretor Comercial e o Diretor de Produção, em reuniões individuais e conjuntas, que foram realizadas durante um período de dois meses. Um roteiro de entrevistas foi utilizado no sentido de direcionar os temas propostos nos objetivos desta pesquisa. Todas as entrevistas foram gravadas e seu conteúdo analisado na íntegra. A amostra é pertinente para aprofundamento das análises, visto que num universo amplo correr-se-ia o risco de apresentar informações genéricas, promovendo uma análise superficial do objeto. A coleta de dados ocorreu em 2012, abrangendo o período de 1992, data de sua fundação, até 2011.

Posteriormente, o conteúdo das entrevistas foi comparado com a Tipologia de Miles e Snow. Portanto, fez-se necessária uma pesquisa em profundidade sob o designer de Pettigrew (1987) para se entender o evento em seu contexto, processo e conteúdo.

\section{CASO JAN BEBIDAS}

Nesta seção será caracterizado objeto de estudo, detalhando o Grupo JAN Bebidas. Na sequência, serão analisadas as informações contrastando-as com o referencial teórico.

\subsection{Caracterização do Objeto}

Segundo informações coletadas com a Direção do Grupo JAN Bebidas, a origem do grupo iniciou a sua história com a distribuidora Água Pura, que foi fundada em 1981.

A partir de algumas viagens ao exterior, verificou-se que no mercado catarinense havia ausência de garrafões de vinte litros retornáveis. Essa empreitada iniciou com um veículo Volkswagen Kombi comercializando cinco garrafões por dia. Assim, empresa Água Pura foi se desenvolvendo com passar do tempo. Contudo, seu maior crescimento ocorreu por meio da parceria com Água Mineral Santa Catarina, uma das mais antigas no mercado. Isso se estendeu até 1992, quando a JAN Bebidas distribuidora absorveu parte dos clientes da Água Pura, por meio de uma concessão, o que possibilitou seu rápido crescimento 6 .

Em 1997, aconteceu a venda da Catarinense Refrigerante para a atual Vonpar, grupo que detém hoje a distribuição da Coca-Cola no sul do país. Porém, a Catarinense Refrigerante manteve a marca Água Mineral Imperatriz.

Como a Vonpar não adquiriu a marca Imperatriz, houve possibilidade de a JAN Bebidas adquirir a concessão dessa marca. Por conta desse cenário de compra da envasadora da Água Mineral Imperatriz e sua marca, os gestores da distribuidora JAN Bebidas propuseram que os gestores da Água Pura fizessem parte da equipe, em virtude de seu enorme know-how e excelente relação com o mercado de distribuição, e assim houve a confluência. Nesse momento, formou-se um novo grupo empresarial, hoje o Grupo JAN.

Atualmente, o Grupo JAN Bebidas detém três empresas: a distribuidora JAN Bebidas, A JAN envasadora (que envasa a Água Mineral Imperatriz) e a Água Pura distribuidora de bebidas.

\subsection{Análise dos dados}

O modelo de seleção natural de Astley e Van de Ven (1983) sugere a ideia de que os gestores agiriam de maneira reativa as condições de seu ambiente. 0 elemento norteador foi a viagem ao exterior dos fundadores da empresa Água Pura, que verificaram o sucesso comercial do produto Água Mineral na embalagem retornável de vinte litros. A oportunidade se apresentava, uma vez que não existia ainda a oferta de embalagens de vinte litros de água e descartáveis no mercado da região da Grande Florianópolis. Ao constatarem essa restrição de mercado, decidiram aproveitar a oportunidade de mercado e, assim, surgiu a Água Pura em 1981, que mais tarde realizaria a fusão com a empresa JAN distribuidora de Bebidas e formaria o Grupo JAN Bebidas.

Desde o início das atividades, o Grupo JAN Bebidas passou por diversas transformações para se manter

${ }^{6}$ No ano de 1992, com a chegada dos senhores José da Costa Bracuhy Neto, André da Costa Baracuhy e Norberto da Costa Baracuhy Junior, vindos dos Estados Unidos da América, houve a abertura de uma nova distribuidora, denominada JAN Bebidas. Utilizando os nomes de seus sócios como inspiração para a marca JAN, José, André e Norberto. 
no ambiente. A primeira crise foi concorrer contra uma empresa, que hoje possui mais de oitenta anos, que possuía a marca mais forte em sua época e ainda comprava marketing share, pois possuía uma grande escala de produção. Por conta deste processo produtivo a mesma conseguia oferecer aos clientes um preço competitivo. A solução do Grupo JAN Bebidas foi investir em distribuição e marca, uma vez que não possuía escala para competir nesse aspecto.

Em 2004, o Grupo JAN conseguiu a licença de conformidade INMETRO, sendo a única a possuir tal licença até hoje. Como resultado de diversas ações, outras premiações vieram, como o reconhecimento da Associação Brasileira das Indústrias Água Mineral, passando pela associação brasileira de embalagens e Top of Mind e Top One da ADVB e prêmio do IBOPE.

Outra necessidade de adaptação foi a alteração do mercado com o plano real e o consequente surgimento da nova classe C. Cabe destacar a concorrência com os filtros de água Europa, considerado como a segunda crise da organização. Com a campanha do "Pare de beber água filtrada", começou a conscientização dos benefícios da água mineral e o programa de fidelização de seus clientes definitivamente iniciou a competição pela conquista da nova classe C. Rapidamente o Grupo Jan Bebidas alcançou a liderança no mercado que ocupa hoje na Grande Florianópolis e cobrando um preço Premium pelos seus produtos.

Outra restrição do mercado foi a mudança na legislação. Em 2008, foi editada a portaria por parte do departamento nacional de produção mineral, que é o órgão regulador a atividade e passou a ter plena vigência em setembro de 2009. Essa portaria decidia que os garrafões retornáveis de dez e vinte litros teriam no máximo três anos de validade. Com essa situação, foi colocada em prática a estratégia dos garrafões exclusivos e com material superior, aqui por voluntarismo de seus diretores. Enquanto a concorrência apenas cumpria a legislação e continua a desenvolver um garrafão padrão.

Os diretores comercial e de produção creditam que as crises por que passaram e, principalmente, a "enorme fome de crescimento", como sendo os elementos centrais e motivadores das mudanças que a empresa tem passado e ainda passará. Desta maneira, valendo-se dos ensinamentos de Miles e Snow (1978), visualiza-se que postura dos gestores, que inicialmente era reativa, atualmente é prospectora.

Os diretores do Grupo JAN Bebidas consideram que as variáveis não controladas pela organização merecem ser monitoradas, pela implicância e relevância com os resultados da organização. Nesse sentido, os clientes, tecnologia, órgãos reguladores e normas são entendidos como variáveis prioritárias.

Em relação aos concorrentes, são monitoradas as grandes corporações mundiais. Visitas, feiras do setor e lançamento são acompanhados de perto. Estados Unidos, Europa e China foram as mais recentes. Cancellier et al. (2009) ressaltam que, na literatura, um dos principais fatores externos considerados influentes para a competitividade organizacional é a concorrência.

Contudo, uma característica investigada em relação às pequenas empresas, por Fann e Smeltzer (1989), é o fato de tais empresas, ao acreditar na qualidade de seu produto, não valorizarem as informações da concorrência. Cancellier e Alberton (2008) verificaram que informações sobre seus clientes e consumidores, normas reguladoras são os mais monitorados, e que realmente informações sobre concorrentes estão entre as menos monitoradas. E isso é o que ocorre com os gestores do Grupo JAN Bebidas.

Considerando que a organização possa ou deva alterar e até se reinventar para se adaptar a este ambiente, novos produtos, novas embalagens, nova identidade visual e opção pela verticalização da organização são algumas de uma série de decisões que poderão ser tomadas pelo Grupo JAN Bebidas.

Pela percepção dos diretores do Grupo JAN Bebidas, a capacidade de escolha estratégica é alta, assim como é alto o grau de determinação ambiental. Diante deste contexto segundo os ensinamentos de Hrebiniak e Joyce (1985), a empresa está posicionada no quadrante da diferenciação. Neste quadrante se apresenta a existência da alta capacidade de escolha, e adaptações com restrições ambientais.

Respondendo à pergunta de Astley e Van de Ven (1983), se a vida organizacional é determinada por restrições ambientais intratáveis, ou é ela criada ativamente por decisões gerenciais estratégicas, a resposta dos gestores do Grupo JAN Bebidas está bem próxima ao que afirma Herbiniak e Joyce (1985) e Rossetto e Rossetto (2005). Segundo estes autores e os gestores da JAN, tais decisões não devem ser excludentes, podendo a cada contexto serem determinadas por restrições do ambiente em que a empresa está inserida e em alguns momentos.

0 estudo longitudinal, realizado junto ao Grupo JAN Bebidas, corrobora com os estudos de Aldrich e Pfeffer (1976 a, 1976b), pois em diversos momentos foi observado que, apesar de parecerem completamente diferentes, tanto o determinismo ambiental como a escolha estratégica, os autores concordam que o ambiente organizacional é importante para a empresa. Este posicionamento é recorrente a todo o momento nas falas dos entrevistados (gestores da JAN).

Pelo que se apurou na entrevista com os diretores do Grupo JAN Bebidas, em relação ao Problema Empreendedor e Soluções, as características foram: 
a) Dimensão Domínio e Expansão de Mercado: Atualmente planejam e já executam a sua expansão com aumento da amplitude de suas linhas de produtos e de aumento em $400 \%$ a mais de seu parque industrial e área geográfica de atuação.

b) Dimensão Postura de Sucesso: Ativa iniciação e mudança; apresentam uma atitude proativa, inovadora e investem tempo e recursos financeiros em encomenda de pesquisas, estudos de designer de novas embalagens e projeto de lançamentos para os próximos quatro anos.

c) Dimensão Monitoramento Ambiental: Orientado para o mercado e ambiente. Acompanhamento do desenvolvimento da tecnologia em feiras no exterior. Recentemente viagens a China, Estados Unidos da América e Europa possibilitaram brainstorm e desenvolvimento da concepção e produção da nova embalagem. Inovando no designer e no material utilizado.

d) Dimensão Crescimento: Desenvolvimento de produtos e mercados e diversificação. A transformação do Grupo JAN Bebidas em uma Holding Companies passa pela transformação em uma empresa de bebidas.

No que tange ao Problema de Engenharia e Soluções, as características foram:

a) Dimensão Objetivo Tecnológico: Flexibilidade e inovação. O investimento em uma nova envasadora e novos estudos apresentam o forte interesse em se atualizar com as inovações mundiais.

b) Dimensão Amplitude Tecnológica: Avançando fronteiras. Pelo objetivo tecnológico e ampliação da capacidade instalada, as fronteiras são expandidas em busca da melhor opção de investimentos.

c) Dimensão Anteparos Tecnológicos: Habilidade do pessoal técnico, diversidade. Investimento em capacitação, treinamentos e auxílio aos funcionários nos estudos superiores são algumas das preocupações do Grupo JAN Bebidas.

Pelo terceiro critério, a relação com o Problema Administrativo e Soluções, as características foram:

a) Dimensão Coalizão Dominante: Marketing e P\&D. Pesquisas tipo Focus Group, estudos de designer e inovação nas embalagens, Preço Premium, distribuições fechadas e padronizadas, capacitação de sua força de vendas, ações publicitárias, campanhas de propaganda são investimentos contínuos do Grupo JAN Bebidas.

b) Dimensão Planejamento: Busca de problemas e oportunidades. A busca de oportunidades é uma característica marcante dos diretores de produção e comercial do Grupo JAN Bebidas. Nas reuniões de diretoria, as apresentações de novas ideias e estratégia são apresentadas em forma de um plano de ação para discussões e tomada de decisões.

c) Dimensão Estrutura: Por produtos e mercados. Sinergia entre as áreas. As áreas comercial e de produção buscam oportunidades, e as áreas administrativas e financeiras buscam as condições da efetivação das ideias.

d) Dimensão Controle: Desempenho do Mercado e volume de vendas. Pelas dimensões anteriores, destacando-se planejamento, coalizão dominante, objetivo tecnológico, domínio e crescimento, os gestores do grupo JAN Bebidas baseiam-se no volume de vendas e o desempenho no mercado para atingir seus objetivos.

No caso atual do Diretor comercial e de produção, a postura é claramente prospectora. O Grupo JAN Bebidas pela postura de sua direção está adotando estrategicamente a ampliação contínua de sua linha de produtos/serviços. Já planejou o desenvolvimento de novos produtos, inclusive o aumento de sua área de atuação. 0 Grupo valoriza ser um dos primeiros a oferecer novas embalagens e produtos.

Diante das análises realizadas, entende-se que o Grupo JAN Bebidas está, segundo as escolhas estratégicas de Hrebiniak e Joyce (1985), localizado no quadrante III. Nesse sentido, observa-se que a empresa preocupa-se com a diferenciação dos seus produtos (Premium); no entanto, ainda existem algumas restrições, em termos de mercados, por conta de grandes grupos multinacionais.

\section{CONCLUSÃO}

Os dados sobre o histórico do Grupo JAN bebidas e suas empresas fundadoras, o desempenho, participação de mercado, e adaptações foram embasados na percepção dos gestores entrevistados.

Com o passar do tempo, o relacionamento com o mercado distribuidor, um maior desenvolvimento do know-how de diversos aspectos que envolvem o seu negócio, as características estratégicas foram alterandose.

Com a verificação das características em relação às dimensões, verificou-se que, atualmente, os gestores assumem uma postura de estratégia prospectora de Miles e Snow (1978).

Pela percepção da comprovada qualidade de seu produto, seja pelo mercado consumidor, seja pelas 
premiações nacionais e internacionais alcançadas, pode-se identificar que o Grupo JAN Bebidas posiciona-se em busca da diferenciação dos seus produtos e serviços, embora ainda possua algumas restrições impostas por grandes grupos do segmento, que são constantemente monitorados.

O Grupo JAN Bebidas, pela qualidade de seu produto, não considera que as informações dos concorrentes devam possuir um sistema de monitoramento com maior frequência. Todavia, existe acompanhamento das informações de grandes corporações, via visitas, feiras do setor e lançamentos de produtos e/ou serviços.

\section{CONSIGNMENT OF STRATEGIES BASED ON ENVIRONMENTAL ANALYSIS: A CASE STUDY IN JAN BEBIDAS GROUP}

\section{ABSTRACT}

The aim of this research was to describe and analyze the adaptive process of JAN Bebidas Group from 1992 to 2010, beginning with the strategic adjustment model proposed by Hrebiniak and Joyce (1985). Other studies were also considered Astley and Van de Ven (1983) and Aldrich and Pfeffer (1976a, 1976b), regarding the strategic changes, and Miles and Snow (1978) model to verify the strategic posture of the directors of JAN Bebidas Group. The study is characterized as longitudinal, qualitative and descriptive in approach. For the investigation, we used the method of case study. For data collection, we used the in-depth interview-based script with the directors of the commercial and production areas. This made it possible to describe the process of strategic adaptation and verify that the main factors of adaptation were caused by environmental restrictions.

Keywords: Strategy. Productive Sector. Beverages.

\section{REFERÊNCIAS}

AGUILAR, F. Scanning the Business Environment. New York: MacMillan,1967.

ALDRICH, H. E.; PFEFFER, J. Organizations and Envioronments. Ithaca: Cornell University, 1976 a.

ALDRICH, H. E.; PFEFFER, J. Environments and Organizations. Annual Review of Sociology, Palo Alto, CA, v. 2, p. 79-105, aug. 1976b.

ANSOFF, I. H. Estratégia Empresarial. São Paulo: McGraw-Hill, 1977.

ASTLEY, W. G.; VAN DE VEN, A. H. Central perspectives and debates in organization theory. Administrative Science Quarterly, Michigan, v. 28, p. 245-273, 1983.

BRITO, V.V.T.; FACHIN, R.C. Decisão estratégica na universidade como resultado da interpretação ambiental: um estudo de caso. In: Encontro anual da Associação Nacional dos Programas de Pós-Graduação em Administração, 26., 2001, Campinas. Anais... Campinas: ANPAD, 2001.

BRUNALDI, K. R.; JUNGLES, A. E.; GIMENEZ, F. A. P. Comportamento estratégico e estilo cognitivo de dirigentes de Pequenas Empresas Construtoras. In: Encontro de Estudos em Estratégia, 3., 2007. Anais... São Paulo: ANPAD,2007.

CANCELLIER, E. L. P. L. A formulação de estratégias em pequenas empresas: um estudo na pequena indústria catarinense. In: Encontro anual da Associação Nacional dos Programas de Pós-Graduação em Administração, 25., 2001. Campinas. Anais... Campinas: ANPAD, 2001.

CANCELLIER. E. L. P. L; ALBERTON, A. A. O monitoramento do ambiente em meios de hospedagem: um estudo comparativo nas regiões de Florianópolis e Balneário Camboriú. Revista Eletrônica de Biblioteconomia e Ciência da Informação, Florianópolis, edição especial, p. 71-88, jul./dez. 2008. 
CANCELLIER, E. L. P. L. et al. 0 monitoramento de informações estratégicas do ambiente externo em pequenas empresas. RIAE - Revista Ibero-Americana de Estratégia, São Paulo, v. 8, n. 1, p. 28-51, jan./ jun. 2009.

CÂNDIDO, G. A.; ABREU, A. F. Aglomerados industriais de pequenas e médias empresas como mecanismo para promoção de desenvolvimento regional. REAd - Revista Eletrônica de Administração, Porto Alegre, v. 6, n. 6, p. 1-26, dez. 2000.

CARNEIRO, J. M. T.; CAVALCANTI, M. A. F. D.; SILVA, J. F. da. Porter revisitado: análise critica da tipologia estratégica do mestre. Revista de Administração Contemporânea, Curitiba, v. 1, n. 3, p. 7-30, 1997.

CONANT, J. S.; MOKWA, M. P.; VARADARAJAN, P. R. Strategic types, distinctive marketing competencies and organizational performance: a multiple measures-based study. Strategic Management Journal, Malden, MA, v. 11, p. 365-383, 1990.

FACHIN, O. Fundamentos de metodologia. 3. ed. São Paulo: Saraiva, 2001.

FANN, G. L; SMELTZER, L. R. The use of information from and about competitors in small business management. Entrepreneurship Theory and Practice, Malden, MA, v. 13, p. 35-43, 1989.

FERNANDES, P. A. A.; SILVA, L. M. F. E.; CÂNDIDO, G. A. Posicionamento estratégico sob o enfoque da diferenciação: um estudo exploratório numa empresa de telecomunicações. In: Encontro Nacional de Engenharia da Produção, 27., 2007, Foz do Iguaçu. Anais... Foz do Iguaçu: ABEPRO, 2007.

FREEMAN, R. E; REED, D. L. Stockholders and Stakeholders: a new perspective on Corporate Governance. California Management Review, Berkeley, CA, v. 25, n. 3, p. 88-106, 1983.

GIL, A. C. Como elaborar projetos de pesquisa. 4. ed. São Paulo: Atlas, 2002.

GIMENEZ, F. A. P. Miles and Snow's strategy model in the context of small firms. In: International Council For Small Business World Conference, 44., Napole, 1999. Procedings... Napole: ICSB, 1999.

GIMENEZ, F. A. P et al. Estratégia em pequenas empresas: uma aplicação do modelo de Miles e Snow. Revista de Administração Contemporânea, Rio de Janeiro, v. 3, n. 2, p. 53-74, maio/ago. 1999.

HAMBRICK, D. C. On the Staying Power of Defenders, Analysers, and Prospectors. Academy of Management Executive, Washington, v. 17, n. 4, p. 115-118, 2003.

HOPPEN, N.; LAPOINTE, L.; MOREAU, E. Um guia para a avaliação de artigos de pesquisa em sistemas de informação. REAd - Revista Eletrônica de Administração, Porto Alegre, v. 2, n. 2, p. 1-34, set./out. 1996.

HREBINIAK, L. G.; JOYCE, W. F. Organizational adaptation: Strategic Choice and environmental Determinism. Administrative Science Quarterly, Michigan, v. 30, p. 336-349, 1985.

MARUCCI, J. C.; MACHADO-DA-SILVA, C. L. Análise da mudança do posicionamento estratégico de bancos comerciais no Brasil. RAM - Revista de Administração Mackenzie, São Paulo, v. 2, n. 2, p. 55-81, 2001.

MCDANIEL, S. W; KOLARI, J. W. Marketing strategy implications of the Miles and Snow strategic typology. Journal of Marketing, Birmingham, AL, v. 51, p. 19-30, 1987.

MILES, R. H. Macro organizational behavior. Glenview: Scott Foresman and Company, 1980.

MILES, R. E.; SNOW, C. C. Organizational strategy, structure, and process. New York: McGraw-Hill, 1978.

MILLER, A.; DESS, G. C. Assessing Porter's (1980) model in terms of its generalizability, accuracy and simplicity. Journal of Management Studies, Malden, MA, v. 30, n. 4, p. 553-585, 1993. 
MINTZBERG, H. Generic Strategies: Toward a Comprehensive Framework. Advances in Strategic Management, Bingley, UK, v. 5, p. 1-67, 1988.

MINTZBERG, H; AHLSTRAND, B.; LAMPEL, J. Safari de estratégia: um roteiro pela selva do planejamento estratégico. Porto Alegre: Bookman, 2000.

MORGAN, G. Imagens da Organização. São Paulo: Atlas, 1995.

MOTTA, P. R. Transformação Organizacional: a teoria e a prática de inovar. Rio de Janeiro: Qualitymark, 2006.

PEREIRA, M. F. Mudanças Estratégicas em Organizações Hospitalares: uma abordagem contextual e processual. Revista de Administração de Empresas, São Paulo, v. 40, n. 3, p. 83-96, jul./set. 2000.

PETTIGREW, A. Context and action in the transformation on the firm. Journal of Management Studies, Malden, MA, v. 24, n. 6, p. 649-670, Nov. 1987.

PORTER, M. Estratégia: a busca da vantagem competitiva. Rio de Janeiro: Campus, 1980.

ROSSETTO, C. R. Comportamento estratégico em empresas familiares na indústria da construção civil setor de edificações: uma aplicação da teoria de Miles e Snow. Revista de Negócios, Blumenau, v. 1, n. 1, p. 1-10, 2000.

ROSSETTO, C. R.; LAZARETI, K.; VARGAS, S. M. L. Adaptação estratégica em uma instituição de educação profissional. Faces: Revista de Administração, Belo Horizonte, v. 12, p. 108-129, 2012.

ROSSETTO, C. R.; ROSSETTO, A. M. A Necessidade da Complementaridade das Perspectivas Institucional e da Dependência de Recursos na Explicação das Mudanças Estratégicas nos Processo de Adaptação Organizacional. In: Encontro Nacional da Associação Nacional dos Programas de Pós-Graduação em Administração (ENANPAD), 27., 2003, Atibaia. Anais... Atibaia: ANPAD, 2003.

ROSSETTO, C. R.; ROSSETTO, A. M. Teoria institucional e dependência de recursos na adaptação organizacional: uma visão complementar. RAE-eletrônica, São Paulo, v. 4, n. 1, jan./jul. 2005.

SILVA, A. B.; REBELO, L. M. B. A emergência do pensamento complexo nas organizações. Revista de Administração Pública, Rio de Janeiro, v. 37, n. 4, p. 777-796, jul./ago. 2003.

SILVEIRA-MARTINS, E.; PREDEBON, E. A.; MAIA, F. L. Adaptação Estratégica no Setor de Transporte Rodoviário de Cargas: 0 Caso da Transportes Simionato. Revista Acadêmica Business Review, Porto Alegre, v. 3, p. 61-80, 2008.

SILVEIRA-MARTINS, E. et al. Modelo de Tuschman e Romanelli: um estudo de caso na Empresa Transportes Simionato Ltda entre 1980 e 2004. In: Mostra de Pesquisa - Organizações e Sociedade, 4., 2006, Biguaçu. Anais... Biguaçu: UNIVALI, 2006.

TREGOE, B.; ZIMMERMAN, J. A estratégia da alta gerência. Rio de Janeiro: Zahar, 1980.

TUSHMAN, M.; NADLER, D. Organizando-se para a inovação. In: STARKEY, K. Como as organizações aprendem. São Paulo: Futura, 1997. p. 166-189.

YIN, R. K. Estudo de Caso: Planejamento e Métodos. 2. ed. Porto Alegre: Bookman, 2001.

ZAHRA, S. A.; PEARCE, J. A. Research Evidence on the Miles-Snow Typology. Journal of Management, v. 16, n. 4, p. 751-768, Dec.1990. 